\title{
PENERAPAN METODE TOPSIS PADA SISTEM PENUNJANG KEPUTUSAN REKOMENDASI MENARA TELEKOMUNIKASI
}

\author{
Rizal Amegia Saputra ${ }^{1}$, Lis Saumi Ramdhani ${ }^{2}$, Medi Firmansyah ${ }^{3}$ \\ 1,2,3 Fakultas Teknologi Informasi, Universitas Bina Sarana Informatika \\ Jl. Cermerlang No.8 Sukakarya, Sukabumi-Jawa Barat. \\ ${ }^{1}$ rizal.rga@bsi.ac.id, ${ }^{2}$ lis.lud@bsi.ac.id, ${ }^{3}$ medi.firmansyah007@gmail.com
}

\begin{abstract}
Abstrak - Menara telekomunikasi merupakan salah satu perangkat keras penunjang utama dalam kelangsungan teknologi informasi saat ini. Layanan Rekomendasi Izin Pembangunan Menara Telekomunikasi dilaksanakan berdasarkan keputusan Bersama Menteri Dalam Negeri, Menteri Pekerjaan umum, Menteri Kominfo dan Kepala BKPM. Hingga tahun 2018, Kabupaten Sukabumi telah memiliki sekitar 582 menara telekomunikasi yang tersebar di daerah perkotaan hingga pelosok. Seluruh menara tersebut tentu saja memerlukan pengawasan dan rekomendasi izin pendiriannya secara terus menerus. Berdasarkan hasil pengolahan instrumen penelitian, dari 17 atribut yang digunakan oleh instansi saat ini dapat disederhanakan menjadi sepuluh atribut antara lain; kecamatan, ketinggian, type menara, jumlah kaki, pengguna, kebersihan bangunan, pagar, grounding, identitas hukum, dan penangkal petir. Dibutuhkan metode khusus yang dapat dijadikan sebagai pendukung dalam menentukan rekomendasi perpanjangan izin menara telekomunikasi di Kabupaten Sukabumi. Pada penelitian ini akan digunakan metode TOPSIS untuk rekomendasi menara telekomunikasi di Kabupaten Sukabumi. Hasil perhitungan sistem rekomendasi menggunakan metode TOPSIS berdasarkan data yang ada saat ini menunjukkan hasil. Berdasarkan perhitungan metode TOPSIS diperoleh nilai jarak alternatif dengan solusi ideal tertinggi adalah 0,784247 untuk No. SKB 383 dan nilai terendah 0,150568 untuk SKB 468.
\end{abstract}

Keywords — TOPSIS, Sistem Penunjang Keputusan, Menara Telekomunikasi.

Abstract-Telecommunication towers are one of the main supporting hardware in the continuity of current information technology. Service Recommendations for Telecommunication Tower Construction Permits are carried out based on the Joint Decree of the Minister of Home Affairs, Minister of Public Works, Minister of Communication and Information and Head of BKPM. Until 2018, Sukabumi Regency has around 582 telecommunications towers spread across urban areas to remote areas. The entire tower, of course, requires supervision and recommendations for its establishment permit continuously. Based on the results of the research instrument processing, of the 17 attributes that are used by the current agency can be simplified into ten attributes, among others; sub-district, altitude, tower type, number of feet, users, cleanliness of buildings, fences, grounding, legal identity, and lightning rods. A special method is needed that can be used as a support in determining recommendations for extension of telecommunications tower licenses in Sukabumi Regency. In this study, the TOPSIS method will be used for the recommendations of telecommunication towers in Sukabumi Regency. The results of the recommendation system calculation using the TOPSIS method based on existing data shows results. Based on the calculation of the TOPSIS method, the alternative distance value with the highest ideal solution is 0.784247 for No. SKB 383 and the lowest score of 0.150568 for SKB 468.

Keywords - TOPSIS, Decision Support Systems, Telecommunication Towers.

\section{PENDAHULUAN}

Menara telekomunikasi merupakan salah satu perangkat keras penunjang utama dalam kelangsungan teknologi informasi saat ini. Layak atau tidaknya pembangunan sebuah menara telekomunikasi atau yang lebih umum dikenal dengan istilah tower dipengaruhi oleh beberapa faktor diantaranya lokasi, type menara, jumlah kaki, bangunan menara, grounding, identitas hukum, penangkal petir, pagar hingga kebersihan area menara telekomunikasi itu sendiri. Perkembangan teknologi dan industri telekomunikasi telah demikian pesatnya. Penempatan menara yang terlalu banyak dan tanpa perencanaan yang tepat akan menimbulkan efek yang kurang baik [1].

Di Indonesia, standard operasional prosedur (SOP) rekomendasi pembangunan menara telekomunikasi secara umum dikeluarkan oleh Dinas Telekomunikasi dan Informatika dari wilayah kabupaten setempat. Layanan Rekomendasi Izin Pembangunan Menara Telekomunikasi dilaksanakan berdasarkan keputusan Bersama Menteri Dalam Negeri, Menteri Pekerjaan umum, Menteri Kominfo 
dan Kepala BKPM No. 18 Tahun 2009, No. 07 / PR/M / 2009, No. 19 / Per / M. Kominfo /03 / 2009 dan No. 3/P/2009 tentang Pedoman dan Penggunaan Menara Telekomunikasi Bersama.

Hingga tahun 2018, Kabupaten Sukabumi telah memiliki sekitar 582 menara telekomunikasi yang tersebar di daerah perkotaan hingga pelosok. Seluruh menara tersebut tentu saja memerlukan pengawasan dan rekomendasi izin pendiriannya secara terus menerus.

Terhitung Januari 2017 proses pengawasan dan rekomendasi izin di Kabupaten Sukabumi masih dikelola secara manual berdasarkan data dan informasi yang diperoleh petugas di lapangan di Dinas Komunikasi, Informatika dan Persandian. Hal ini tentu saja menghabiskan banyak waktu dan tenaga kerja yang digunakan untuk membuat sebuah rekomendasi.

Peningkatan kualitas dan kuantitas komoditas Sistem rekomendasi dapat diperoleh dengan beberapa metode pengambil keputusan diantaranya Simple Additive Weighting (SAW), Analytic Hierarchy Process (AHP), Weighted Product (WP), ELECTRE dan Technique for Order Preference by Similarity to Ideal Solution (TOPSIS). Melalui implementasi metode simple additive weighting dapat ditentukan lokasi potensial untuk membangun menara baru berbasis website yang dapat melihat lokasi penempatan BTS existing ataupun menara baru dengan google maps ataupun image yang telah diolah dari MapInfo [2].

Metode Simple Additive Weighting (SAW) disarankan untuk menyelesaikan masalah penyeleksian dalam pengambilan keputusan multi proses. Sedangkan metode Technique for Order Performance of Similarity to Ideal Solution (TOPSIS) menggunakan prinsip bahwa alternatif yang terpilih harus mempunyai jarak terpanjang (terjauh) dari solusi ideal negatif dari sudut pandang geometris dengan menggunakan kedekatan relatif dari suatu alternative, Dari hasil pengujian sistem, perbandingan metode TOPSIS dan SAW, diperoleh hasil bahwa metode TOPSIS lebih tepat digunakan dalam pemberian reward pelanggan Depot Air Minum [3].

Pada penelitian ini akan digunakan metode TOPSIS untuk rekomendasi menara telekomunikasi di Kabupaten Sukabumi.

\section{TINJAUAN PUSTAKA}

\section{A. Sistem Penunjang Keputusan}

Sistem Pendukung Keputusan (SPK) merupakan suatu pendekatan atau metodologi untuk mendukung keputusan [4]. SPK menggunakan CBIS (Computer Based Information System) yang fleksibel, interaktif dan dapat diadaptasi, yang dikembangkan untuk mendukung solusi untuk masalah manajemen spesifik yang tidak terstruktur. SPK menggunakan data, memberikan antarmuka pengguna yang mudah dan dapat menggabungkan pemikiran pengambil keputusan. SPK pada umumnya menggunakan berbagai model dan dibangun oleh suatu proses interaktif dan iterative. SPK mendukung semua fase pengambilan keputusan dan dapat memasukkan suatu komponen pengetahuan. SPK dapat digunakan oleh pengguna tunggal pada satu PC atau bisa menjadi berbasis Web untuk digunakan oleh banyak orang pada beberapa lokasi yang berbeda.

Tahap-tahap Pengambilan Keputusan yaitu:

1. Identifikasi masalah

2. Pemilihan metode

3. Pengumpulan data yang dibutuhkan untuk melaksanakan model keputusan tersebut.

4. Mengimplementasikan model tersebut

5. Mengevaluasi sisi positif dari setiap alternatif yang ada

6. Melaksanakan solusi terpilih.

\section{B. Sistem Rekomendasi}

Sistem Rekomendasi (SR) merupakan model aplikasi dari hasil observasi terhadap keadaan dan keinginan pelanggan [5]. Sistem Rekomendasi memanfaatkan opini seseorang terhadap suatu barang dalam domain atau kategori tertentu, untuk membantu seseorang dalam memilih produk. Oleh karena itu sistem rekomendasi memerlukan model rekomendasi yang tepat agar apa yang direkomendasikan sesuai dengan keinginan pelanggan, serta mempermudah pelanggan mengambil keputusan yang tepat dalam menentukan produk yang akan dibelinya.

Banyak metode atau teknik yang dapat digunakan dalam sistem rekomendasi. Setiap metode disesuaikan dengan permasalahan dalam menghasilkan sebuah informasi yang sesuai.

\section{TOPSIS}

Technique for Order Preference by Similarity to Ideal Solution (TOPSIS) didasarkan pada konsep dimana alternatif terpilih yang terbaik tidak hanya memiliki jarak terpendek dari solusi ideal positif, namun juga memiliki jarak terpanjang dari solusi ideal negatif.

Langkah-langkah penyelesaian masalah yang memiliki model Multiple Attribute Decision Making (MADM) dengan TOPSIS sebagai berikut:

1. Membuat matriks keputusan yang ternormalisasi.

2. Membuat matriks keputusan yang ternormalisasi terbobot.

3. Menentukan matriks solusi ideal positif \& matriks solusi ideal negatif.

4. Menentukan jarak antara nilai setiap alternatif dengan matriks solusi ideal positif dan matriks solusi ideal negatif.

5. Menentukan nilai preferensi untuk setiap alternatif.

TOPSIS membutuhkan rating kinerja setiap alternatif $\mathrm{Ai}$ pada setiap kriteria $\mathrm{Cj}$ yang ternormalisasi, yaitu: 


$$
r_{i j}=\frac{x_{i j}}{\sqrt{\sum_{i=1}^{m} x_{i j}^{2}}}
$$

Page | 139 i=1,2,...m; dan $j=1,2, \ldots . n$.

Solusi ideal positif A+ dan solusi ideal negatif Adapat ditentukan berdasarkan rating bobot ternormalisasi (yij) sebagai:

$$
y_{i j}=w_{i} r_{i j}
$$

$\mathrm{i}=1,2, \ldots . \mathrm{m}$; dan $\mathrm{j}=1,2, \ldots . \mathrm{n}$.

$$
\begin{aligned}
& A^{+}=\left(y_{1}^{+}, y_{2}^{+}, \cdots, y_{n}^{+}\right), \\
& A^{-}=\left(y_{1}^{-}, y_{2}^{-}, \cdots, y_{n}^{-}\right),
\end{aligned}
$$

dengan

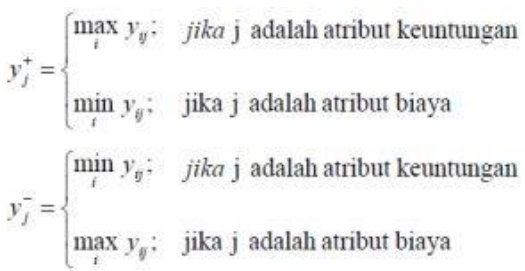

Jarak antara alternatif Ai dengan solusi ideal negatif dirumuskan sebagai:

Nilai Vi yang lebih besar menunjukkan bahwa alternatif Ai lebih dipilih.

$$
D_{i}^{-}=\sqrt{\sum_{j=1}^{n}\left(y_{i j}-y_{i}^{-}\right)^{2}} ;
$$

Jarak antara alternatif Ai dengan solusi ideal positif dirumuskan sebagai:

$$
V_{i}=\frac{D_{i}}{D_{i}^{-}+D_{i}^{+}}
$$

\section{Menara Telekomunikasi}

Menurut Peraturan Menteri Komunikasi Dan Informatika Nomor: /PER/M.KOMINFO/ /2007 Menara telekomunikasi, yang selanjutnya disebut menara, adalah bangunan yang berfungsi sebagai penunjang jaringan telekomunikasi yang desain/bentuk konstruksinya disesuaikan dengan keperluan jaringan telekomunikasi.

Penyelenggara telekomunikasi yang dimaksud dapat berupa perseorangan, koperasi, badan usaha milik daerah, badan usaha milik negara, badan usaha swasta, instansi pemerintah, dan instansi pertahanan keamanan negara.

\section{E. Metode analisa}

Metoda analisa data dalam penelitian ini menggunakan pendekatan deskriptif kuantitatif. Penelitian kuantitatif merupakan penelitian untuk menemukan pengetahuan yang menggunakan data berupa angka sebagai alat untuk menganalisa mengenai apa yang diketahui [6].

Sedangkan metode deskriptif merupakan metode dalam meneliti suatu objek dengan tujuan untuk memberikan gambaran secara sistematis, faktual, dan aktual mengenai objek yang diselidiki [7].

\section{METODOLOGI PENELITIAN}

\section{Perangka Penelitian}

Penelitian ini secara umum dapat diklasifikasikan menjadi tiga tahapan seperti pada gambar 1 kerangka penelitian di bawah ini:

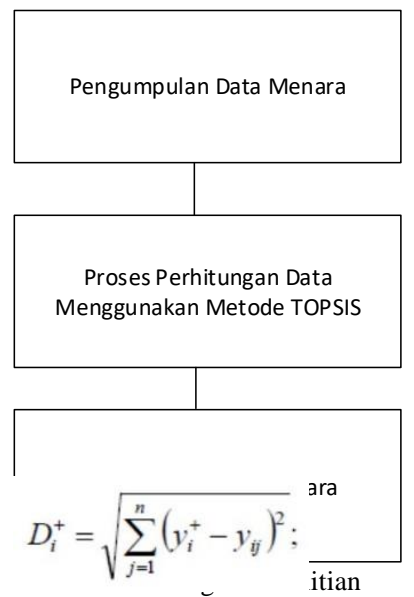

Hasil akhir yang diharapkan dari penelitian ini adalah memperoleh data hasil olahan secara terkomputerisasi yang mampu memberikan rekomendasi izin perpanjangan maupun pendirian menara baru di Kabupaten Sukabumi. Data yang digunakan adalah data sekunder yang digunakan oleh Dinas Telekomunikasi Informatika dan Persandian Kabupaten Sukabumi.

\section{B. Instrument Penelitian}

Pada penelitian ini menggunakan jumlah populasi awal sebanyak 582 instance. Semua data yang digunakan diperoleh dari Dinas Telekomunikasi Informatika dan Persandian Kabupaten Sukabumi.

Terdapat 17 (tujuh belas) atribut awal yang terdapat pada data rekapitulasi menara telekomunikasi di Kabupaten Sukabumi sebagai berikut; nama pemilik, alamat, desa, kecamatan, lat, long, ketinggian, type menara, jumlah kaki, pengguna menara, nomor SKB, bangunan menara, grounding, identitas hukum, penangkal petir, pagar, dan kebersihan. Atribut-atribut tersebut umumnya bertipe data string, numeric dan boolean.

Agar dapat diolah menggunakan metode perhitungan TOPSIS, data-data dirubah ke dalam 
bentuk numerik mengikuti bentuk skala yang diklasifikasikan menjadi sebagai berikut:

\section{Kecamatan}

Khusus untuk atribut kecamatan yang ada pada Page | 140 data menara telekomunikasi di Kabupaten Sukabumi ini diperoleh hasil olahan berdasarkan jumlah menara yang sudah ada di setiap kecamatan seperti pada tabel 1 di bawah ini:

TABEL I

REKAP JUMLAH MENARA PER KECAMATAN DI KABUPATEN SUKABUMI

\begin{tabular}{|c|c|c|}
\hline Nama Kecamatan & $\begin{array}{l}\text { Jumlah } \\
\text { Menara }\end{array}$ & Likert \\
\hline Palabuhanratu & 38 & 5 \\
\hline Cicurug & 31 & 4 \\
\hline Cisaat & 30 & 4 \\
\hline Cikembar & 26 & 4 \\
\hline Sukaraja & 24 & 3 \\
\hline Simpenan & 23 & 3 \\
\hline Cisolok & 22 & 3 \\
\hline Cibadak & 18 & 3 \\
\hline Jampang Tengah & 18 & 3 \\
\hline Sukabumi & 18 & 3 \\
\hline Nagrak & 17 & 2 \\
\hline Parungkuda & 15 & 2 \\
\hline Cikidang & 14 & 2 \\
\hline Nyalindung & 14 & 2 \\
\hline Sagaranten & 14 & 2 \\
\hline Cicantayan & 12 & 2 \\
\hline Ciemas & 12 & 2 \\
\hline Ciracap & 12 & 2 \\
\hline Gunungguruh & 12 & 2 \\
\hline Sukalarang & 12 & 2 \\
\hline Surade & 12 & 2 \\
\hline Bantar Gadung & 11 & 2 \\
\hline Kalapanunggal & 11 & 2 \\
\hline Warungkiara & 11 & 2 \\
\hline Jampangkulon & 10 & 2 \\
\hline Kadudampit & 10 & 2 \\
\hline Tegal Buleud & 10 & 2 \\
\hline Cikakak & 8 & 1 \\
\hline Cireunghas & 8 & 1 \\
\hline Lengkong & 8 & 1 \\
\hline Pabuaran & 8 & 1 \\
\hline Waluran & 8 & 1 \\
\hline Caringin & 7 & 1 \\
\hline Cibitung & 7 & 1 \\
\hline Cidolog & 7 & 1 \\
\hline Parakansalak & 7 & 1 \\
\hline Purabaya & 7 & 1 \\
\hline Bojonggenteng & 6 & 1 \\
\hline Cidahu & 6 & 1 \\
\hline Gegerbitung & 6 & 1 \\
\hline Kabandungan & 6 & 1 \\
\hline Kalibunder & 6 & 1 \\
\hline Ciambar & 5 & 1 \\
\hline Kebonpedes & 5 & 1 \\
\hline Cidadap & 4 & 1 \\
\hline Curugkembar & 3 & 1 \\
\hline Cimanggu & 2 & 1 \\
\hline
\end{tabular}

Sumber: Data olahan
Berdasar data tersebut di atas diketahui jumlah menara paling banyak adalah Kecamatan Palabuhan Ratu dengan 38 menara dan paling sedikit adalah kecamatan Cimanggu dengan dua buah menara saja. Oleh karena itu atribut kecamatan dapat diklasifikasikan berdasarkan jumlah menara yang sudah ada saat ini menurut skala Likert sebagai berikut:

Jumlah menara 2-9 = 1

Jumlah menara $10-17=2$

Jumlah menara $18-24=3$

Jumlah menara $25-31=4$

Jumlah menara $32-38=5$

2. Ketinggian

Untuk ketinggian menara bervariasi dari tinggi 32 meter sampai dengan 198 meter.

TABEL II

REKAP JUMLAH MENARA PER KETINGGIAN DI KABUPATEN SUKABUMI

\begin{tabular}{|c|c|c|}
\hline $\begin{array}{c}\text { Tinggi } \\
(\text { meter })\end{array}$ & $\begin{array}{c}\text { Jumlah } \\
\text { Menara }\end{array}$ & Likert \\
\hline 198 & 1 & 5 \\
\hline 92 & 1 & 5 \\
\hline 90 & 3 & 5 \\
\hline 72 & 172 & 4 \\
\hline 71 & 1 & 4 \\
\hline 70 & 27 & 4 \\
\hline 65 & 1 & 4 \\
\hline 64 & 11 & 4 \\
\hline 63 & 1 & 4 \\
\hline 62 & 73 & 4 \\
\hline 60 & 13 & 3 \\
\hline 55 & 4 & 3 \\
\hline 52 & 64 & 3 \\
\hline 50 & 1 & 3 \\
\hline 45 & 10 & 2 \\
\hline 42 & 48 & 2 \\
\hline 40 & 1 & 2 \\
\hline 36 & 7 & 1 \\
\hline 35 & 2 & 1 \\
\hline 32 & 10 & 1 \\
\hline
\end{tabular}

Sumber: Data olahan

3. Type menara; yang terdiri dari $\mathrm{SST}=3$, RoofTop $=2$, Combat $=1$

4. Jumlah kaki

5. Pengguna; bervariasi mulai dari satu pengguna sampai dengan lima pengguna menara telekomunikasi.

6. Kebersihan bangunan; diklasifikasikan sebagai berikut:

7. Jika bangunan baik dan kebersihan baik $=5$

8. Jika bangunan baik dan kebersihan kotor $=4$

9. Jika bangunan cat ulang dan kebersihan baik $=3$

10. Jika bangunan cat ulang dan kebersihan kotor $=2$

11. Jika bangunan - dan kebersihan - = 1

12. Pagar; dikategorikan sebagai berikut: baik $=5$, ada $=4$, kotor $=3$, perbaikan $=2$, tidak ada $=1$. 
13. Grounding; dengan kategori: ada $=2$, tidak ada $=$ 1.

14. Identitas hukum; dengan kategori: ada $=2$, tidak ada $=1$.

15. Penangkal petir; dengan kategori: ada $=2$, tidak ada $=1$.

Dari 17 atribut awal, disederhanakan menjadi 10 atribut yang dapat dikategorikan sebagai atribut paling berpengaruh terhadap sistem rekomendasi menara telekomunikasi di Kabupaten Sukabumi.

\section{Metode Pengumpulan Data, Populasi dan Sample Penelitian}

Metode pengumpulan data menggunakan data sekunder. Data yang sudah direkap dan digunakan sebelumnya oleh Dinas Telekomunikasi Informatika dan Persandian Kabupaten Sukabumi.

Populasi data awal yang digunakan pada penelitian ini berjumlah 582 instance atau record. Tidak seluruh populasi dalam data dapat digunakan pengujian metode. Oleh karenanya masih diperlukan tahap analisis data agar dapat diperoleh populasi data yang sesuai dengan kebutuhan perhitungan metode TOPSIS. Berikut ini Sebagian sample data awal yang digunakan pada penelitian ini sebagai berikut:

TABEL III

SAMPLE DATA AWAL

\begin{tabular}{|l|l|c|c|c|}
\hline No & Nama & $\begin{array}{l}\text { Type } \\
\text { Menara }\end{array}$ & $\begin{array}{l}\text { Ketinggia } \\
\mathrm{n}\end{array}$ & $\begin{array}{l}\text { Jns } \\
\text { Kak }\end{array}$ \\
\hline 1 & TBG & SST & $52 \mathrm{~m}$ & 4 \\
\hline 2 & Telkomsel & SST & $72 \mathrm{~m}$ & 4 \\
\hline 3 & IBS & SST & $72 \mathrm{~m}$ & 4 \\
\hline 4 & Protelindo & SST & $62 \mathrm{~m}$ & 3 \\
\hline 5 & TBG & SST & $72 \mathrm{~m}$ & 4 \\
\hline 6 & Telkomsel & SST & $72 \mathrm{~m}$ & 4 \\
\hline 7 & Protelindo & SST & $42 \mathrm{~m}$ & 3 \\
\hline 8 & Indosat & SST & $62 \mathrm{~m}$ & 4 \\
\hline 9 & XL & SST & $52 \mathrm{~m}$ & 3 \\
\hline 10 & TBG & SST & $32 \mathrm{~m}$ & 4 \\
\hline
\end{tabular}

Sumber: DKIP Kab. Sukabumi

Berdasarkan data tersebut di atas masih diperlukan proses persiapan data agar dapat diolah menggunakan metode TOPSIS. Persiapan data tersebut meliputi proses konversi string menjadi data numerical, pengklasifikasian masing-masing record menurut skala likert, dan pembersihan data kosong atau null.

Teknik Sampling yang digunakan pada penelitian ini adalah menggunakan semua data yang ada dalam proses perhitungan nilai maksimal maupun minimal.

\section{PEMBAHASAN}

A. Algoritma Technique for Order Performance of Similarity to Ideal Solution (TOPSIS)

Pada penelitian ini, dibutuhkan proses penentuan kriteria agar diperoleh hasil perhitungan metode TOPSIS yang mendekati objektif. Kriteria yang digunakan dalam algoritma TOPSIS pada umumnya sama dengan kriteria yang digunakan pada algoritma sistem rekomendasi lainnya. Dimana proses pertama yang dilakukan adalah menentukan standar nilai bobot, yang dapat dilihat pada tabel 4.1 standar nilai algoritma TOPSIS di bawah ini:

TABEL IV STANDARD NILAI ALGORITMA TOPSIS

\begin{tabular}{|c|c|}
\hline Nilai & Keterangan \\
\hline $\mathbf{1}$ & Sangat Rendah \\
\hline $\mathbf{2}$ & Rendah \\
\hline $\mathbf{3}$ & Cukup \\
\hline $\mathbf{4}$ & Tinggi \\
\hline $\mathbf{5}$ & Sangat Tinggi \\
\hline
\end{tabular}

Salah satu proses seleksi untuk sistem rekomendasi menara telekomunikasi di Kabupaten Sukabumi adalah menentukan jenis dan bobot masingmasing kriteria atau atribut yang menjadi penilaian penting. Hal tersebut dapat dilihat pada tabel 4.2 kriteria sistem rekomendasi menara telekomunikasi Kabupaten Sukabumi sebagai berikut:

TABEL V

KRITERIA SISTEM REKOMENDASI MENARA TELEKOMUNIKASI KABUPATEN SUKABUMI

\begin{tabular}{|l|l|l|}
\hline Kode & Kriteria & $\begin{array}{l}\text { Jenis } \\
\text { Kriteria }\end{array}$ \\
\hline C1 & Kecamatan & Tinggi \\
\hline C2 & Ketinggian & $\begin{array}{l}\text { Sangat } \\
\text { Tinggi }\end{array}$ \\
\hline C3 & Type menara & Tinggi \\
\hline C4 & Jumlah kaki & Cukup \\
\hline C5 & Pengguna & Rendah \\
\hline C6 & $\begin{array}{l}\text { Kebersihan } \\
\text { bangunan }\end{array}$ & Cukup \\
\hline C7 & Pagar & Rendah \\
\hline C8 & Grounding & Cukup \\
\hline C9 & $\begin{array}{l}\text { Identitas } \\
\text { hukum }\end{array}$ & Tinggi \\
\hline C10 & Penangkal petir & Cukup \\
\hline
\end{tabular}

Sumber: Data olahan

Berikut ini adalah penyelesaian kasus merekomendasikan menara telekomunikasi dengan menentukan nilai pembagi dan pembobot menggunakan rumus (1) dan (2) diperoleh hasil:

TABEL VI

NILAI PEMBAGI BERDASARKAN PERHITUNGAN RUMUS (1)

\begin{tabular}{|l|l|l|}
\hline Kode & Kriteria & $\begin{array}{l}\text { Nilai } \\
\text { Pembagi }\end{array}$ \\
\hline C1 & Kecamatan & 55,3444 \\
\hline C2 & Ketinggian & 75,4586 \\
\hline C3 & Type menara & 63,7103 \\
\hline
\end{tabular}




\begin{tabular}{|l|l|l|}
\hline C4 & Jumlah kaki & 77,4016 \\
\hline C5 & Pengguna & 34,2199 \\
\hline C6 & Kebersihan bangunan & 101,5037 \\
\hline C7 & Pagar & 105,3328 \\
\hline C8 & Grounding & 42,2611 \\
\hline C9 & Identitas hukum & 36,5923 \\
\hline C10 & Penangkal petir & 42,1900 \\
\hline
\end{tabular}

Sumber: Data olahan

Selanjutnya adalah menentukan solusi ideal positif A+ dan solusi ideal negatif A- yang dapat ditentukan berdasarkan rating bobot ternormalisasi (yij) menggunakan rumus (3) dan (4) sebagai berikut:

TABEL VII

NILAI PEMBAGI BERDASARKAN PERHITUNGAN RUMUS (1)

\begin{tabular}{|l|l|l|l|}
\hline Kode & Kriteria & $\begin{array}{l}\text { Nilai } \\
\text { A+ }\end{array}$ & Nilai A- \\
\hline C1 & KECAMATAN & 0,0226 & 0,0045 \\
\hline C2 & KETINGGIAN & 0,0027 & 0,0133 \\
\hline C3 & TYPE MENARA & 0,0118 & 0,0118 \\
\hline C4 & JUMLAH KAKI & 0,0129 & 0,0172 \\
\hline C5 & PENGGUNA & 0,0000 & 0,0731 \\
\hline C6 & $\begin{array}{l}\text { KEBERSIHAN } \\
\text { BANGUNAN }\end{array}$ & 0,0066 & 0,0164 \\
\hline C7 & PAGAR & 0,0047 & 0,0237 \\
\hline C8 & GROUNDING & 0,0079 & 0,0158 \\
\hline C9 & $\begin{array}{l}\text { IDENTITAS } \\
\text { HUKUM }\end{array}$ & 0,0068 & 0,0137 \\
\hline C10 & $\begin{array}{l}\text { PENANGKAL } \\
\text { PETIR }\end{array}$ & 0,0079 & 0,0158 \\
\hline
\end{tabular}

Sumber: Data olahan

Kemudian untuk jarak antara alternatif Ai dengan solusi ideal negatif dan nilai Vi yang lebih besar menunjukkan bahwa alternatif Ai lebih dipilih, akan digunakan rumus (5) dan (6).

Algoritma terkahir adalah melakukakn pencarian nilai preferensi untuk setiap alternatif (Vi) dengan rumus (7)

$$
\begin{aligned}
& V i=\frac{\begin{array}{c}
\text { Perhitungan: } \\
0,0753
\end{array}}{0,0753+0,0206}=0,7842(\text { No.SKB 383) } \\
& V n=\frac{0,0159}{0,0159+0,0779}=0,1506(\text { No.SKB 468) }
\end{aligned}
$$

\section{B. Pengujian dan Hasil}

Pengujian yang dilakukan adalah pengujian metode (method testing) dengan menggunakan metode TOPSIS. Metode TOPSIS adalah sebuah kerangka untuk mengambil keputusan dengan efektif. Pengujian metode berfokus pada tindakan pengguna yang terlihat dan pengguna dapat mengenali output dari sistem, pengujian ini menjalankan sistem pada lingkungan yang aktif dengan menggunakan data yang benar. Pada tahap ini pengujian pada administrator yang memiliki hak akses sepenuhnya pada sistem. Hasil yang di dapat dari sistem ini mampu memberikan keputusan terbaik dalam pemberian rekomendasi izin perpanjangan maupun pendirian baru menara telekomunikasi di Kabupaten Sukabumi.

Hasil perhitungan atau pengolahan data menara telekomunikasi menggunakan metode TOPSIS menunjukkan hasil akhir dimana Nilai Vi yang lebih besar menunjukkan bahwa alternatif No. SKB 383 adalah menara yang paling direkomendasikan dengan nilai 0,7842 . Sedangkan nilai Vi terendah atau yang hampir tidak direkomendasikan adalah menara telekomunikasi dengan No. SKB 468 yang memperoleh nilai Vi sebesar 0,1506 saja.

Demikianlah range antara nilai Vi terbesar hingga nilai Vi terkecil memiliki gap atau selisih sebesar 0,63368 . Nilai tersebut menunjukkan bahwa terdapat perbedaan yang cukup tinggi dari masing 2 menara.

\section{PENUTUP}

Pada data awal yang digunakan dalam penelitian ini terdapat tujuh belas atribut sebagai penunjang dalam pengambilan keputusan sistem rekomendasi izin baru dan perpanjangan menara telekomunikasi di Kabupaten Sukabumi. Berdasarkan hasil pengolahan instrumen penelitian ternyata hanya dibutuhkan sepuluh atribut antara lain; Kecamatan, Ketinggian, Type menara, Jumlah kaki, Pengguna, Kebersihan bangunan, Pagar, Grounding, Identitas hukum, dan Penangkal petir. Sedangkan No. SKB dijadikan sebagai acuan kepentingan dari sistem rekomendasi yang dimaksud. Hasil perhitungan sistem rekomendasi menggunakan metode TOPSIS berdasarkan data yang ada saat ini menunjukkan hasil. Berdasarkan perhitungan metode TOPSIS diperoleh nilai jarak alternatif dengan solusi ideal tertinggi adalah 0,7842 untuk No. SKB 383 dan nilai terendah 0,1506 untuk SKB 468.

\section{SARAN}

Penggunaan metode TOPSIS pada penelitian ini masih menggunakan perhitungan manual. Namun demikian sudah diminimalisir dari kemungkinan kesalahan perhitungan. Akan lebih baik jika digunakan perangkat pendukung atau tools yang dapat digunakan untuk menghitung TOPSIS secara terkomputerisasi.

Untuk penelitian selanjutnya, hasil rekomendasi sebagai penunjang keputusan ini dapat diterapkan ke dalam sebuah program aplikasi agar dapat digunakan menjadi lebih mudah oleh instansi terkait.

\section{UCAPAN TERIMA KASIH}

Penulis mengucapkan terima kasih kepada semua pihak yang telah membantu baik secara moril maupun materil terhadap penelitian ini. 


\section{REFERENSI}

[1] E. Sasongko, E. T. Sasongko, and A. Mauludiyanto, "Perencanaan dan Penataan Menara Telekomunikasi Seluler di Kabupaten Sidoarjo menggunakan MapInfo," J. Tek. ITS, vol. 4, no. 1, pp. A124-A129, Mar. 2015.

[2] L. Christine, L. A. Christine, and A. Mauludiyanto, "Sistem Pendukung Keputusan Perencanaan Penempatan Lokasi Potensial Menara Baru Bersama Telekomunikasi Seluler Di Daerah Sidoarjo Menggunakan Metode Simple Additive Weighting (SAW),"J. Tek. ITS, vol. 4, no. 1, pp. A31-A35, Mar. 2015.

[3] A. Perdana Windarto Program Studi Sistem Informasi and S. A. Tunas Bangsa Pematangsiantar Jln Jenderal Sudirman Blok No, "Implementasi Metode Topsis Dan SAW Dalam Memberikan Reward Pelanggan," Kumpul. J. Ilmu Komput., vol. 04, 2017.

[4] D. Nofriansyah, Konsep Data Mining Vs Sistem Pendukung Keputusan. 2014.

[5] B. S. L McGinty, "Systems, Adaptive Selection: analysis of critiquing and preference based feed back in conversational recommender," in International Journal of Electronic Commerce, 2006, pp. 35-37.

[6] Y. Farlina and J. M. Hudin, "Kajian Kepuasan Pengguna Informasi Penerimaan Peserta Didik Baru ( PPDB ) Online," Kaji. Kepuasan Pengguna Inf. Penerimaan Peserta Didik Baru Online, vol. 2, no. 2, pp. 48-54, 2017.

[7] N. Nopianti, T. Silvana, and A. Budiono, "Sikap Pengunjung Terhadap Ketersediaan,” J. Kaji. Inf. Perpust., vol. 4, no. 1, pp. 29-36, 2016. 